\title{
Lombok Living Strategy After the Lombok Earthquake
}

\author{
Hemi Wulan Martatiwi, Nurhadi, Chatarina Muryani \\ Pascasarjana Universitas Sebelah Maret \\ hemiwulan@gmail.com
}

\section{Article History}

accepted 31/08/2020

\begin{abstract}
This study aims to determine the form of household livelihood strategies found in Kayangan District after the earthquake. This qualitative research uses the case study method by sampling using purposive sampling. The sample used in this study were 60 households. Data collection techniques in this study used triangulation. Triangulation used in this research is by using source triangulation. In addition, other data collection techniques are in the form of observation, deep interview, and documentation. Analysis of the data used in this study is a qualitative analysis using the Miles and Huberman models. Activities carried out in the analysis are in the form of scoring data, reduction, data display, and conclusion drawing / verification. The results of the study concluded that: Household livelihood strategies used by the community in Kayangan District include intensification and exensification, as well as diversification.
\end{abstract}

Keywords: Earthquake, Community, Household, And Livelihood Strategy.

\begin{abstract}
Abstrak
Penelitian ini bertujuan untuk mengetahui bentuk strategi penghidupan rumah tangga yang terdapat di Kecamatan Kayangan pasca gempa bumi. Menggunakan metode studi kasus dengan menggunakan purposive sampling. Sampel yang digunakan sebanyak 60 rumah tangga. Teknik pengumpulan data menggunakan triangulasi. Triangulasi yang digunakan yaitu dengan menggunakan triangulasi sumber. Selain itu, teknik pengumpulan data lainnya yaitu berupa observasi, wawancara mendalam, dan dokumentasi. Analisis data yang digunakan adalah analisis kualitatif dengan menggunakan model Miles dan Huberman. Hasil penelitian disimpulkan bahwa: Strategi penghidupan rumah tangga yang digunakan oleh masyarakat Kayangan yaitu antara lain intensifikasi dan eksensifikasi, serta diversifikasi. Bentuk strategi intensifikasi yang dilakukan rumah tangga di Kayangan yaitu berupa pemanfatan lahan pertanian, dan pemafaatan lahan pekarangan sebagai cara pemenuhan hidup dalam proses pemulihan pasca gempa bumi. Sedangkan, bentuk strategi diversifikasi yang dliakukan rumah tangga Kayangan yaitu meliputi kegiatan pertanian diluar bercocok tanam, sektor perdagangan, sektor jasa, penghasilan dari modal, pengolahan dan pemasaran hasil pertanian.
\end{abstract}

Kata kunci : Gempabumi, Masyarakat, Rumah Tangga, Dan Strategi Penghidupan.

Social, Humanities, and Education Studies (SHEs): Conference Series https://jurnal.uns.ac.id/shes 


\section{PENDAHULUAN}

Indonesia adalah negara yang terdiri dari kepulauan yang membentang luas. Selain itu, wilayah Indonesia terletak pada 3 lempeng tektonik dunia yaitu lempeng Indo-Australia, Eurasia dan lempeng Pasifik serta merupakan jalur yang dilewati oleh The Pasific Ring of Fire atau Cincin Api Pasifik (Amri et al., 2006). Indonesia juga dilalui oleh dua jalur pegunungan aktif di dunia yaitu Sirkum Pasifik dan Sirkum Mediterania (Hermon, 2015). Sejarah gempa bumi di Indonesia cukup panjang, Indonesia terletak pada lajur sumber gempa yang membentang sepanjang tidak kurang dari 5.600 km, mulai dari Andaman sampai busur Banda Timur sehingga merupakan wilayah yang rawan terhadap gempa bumi (Sukandarrumidi, 2010). Ketiga zona lempeng tersebut memberikan kontribusi sebesar $90 \%$ kejadian gempa bumi dan didominasi oleh gempa dengan kategori besar (National Agency for Disaster Management (BNPB), 2015).

Salah satu daerah rawan dengan bencana gempa bumi yaitu Propinsi Nusa Tenggara Barat (Sukandarrumidi, 2010). Nusa Tenggara Barat merupakan wilayah yang dilalui oleh jalur mediterania, sehingga di wilayah ini sering terjadi gempa-gempa tektonik dan vulkanik (Hartuti, 2009). Secara geologis, Provinsi Nusa Tenggara Barat merupakan kawasan seismik aktif sehingga wilayah ini berpotensi terjadinya gempa bumi karena terletak diantara dua pembangkit gempa yaitu dari selatan dan utara (Christanto, 2011). Pada bagian selatan terdapat zona subduksi lempeng IndoAustralia yang menunjam ke bawah Pulau Lombok sedangkan dari utara terdapat struktur geologi sesar naik Flores (Flores Back Arc Thrusting), sesar naik ini memiliki jalur memanjang dari laut Bali ke sebelah timur hingga menuju laut Flores sehingga aktivitas gerakan sesar tersebut sangat dekat dengan Pulau Lombok.

Gempa bumi dapat menjadi bencana apabila terjadi di wilayah hunian manusia dan menimbulkan potensi kerugian serta menjadi penghalang terjadinya aktivitas ekonomi dan sosial. Aktivitas alam yang berbahaya dapat berubah menjadi bencana apabila manusia tersebut tidak mempunyai daya tahan yang kuat untuk menghadapinya (Wiarto, 2017). Potensi kerugian tersebut dapat dilihat dari beberapa indikator seperti persentase bangunan yang terbuat dari kayu, kepadatan bangunan, dan kepadatan industri berbahaya (Yustiningrum, 2016). Hal tersebut sangat memberi dampak kerugian bagi kehidupan, terutama apabila gempa bumi tersebut terjadi di daerah yang terdapat aktivitas padat penduduk di dalamnya sehingga dapat mengakibatkan bencana dan banyak kerugian yang ditimbulkan.

Kerentananan pasca bencana alam dapat meliputi kerentananan politik, ekonomi, sosial, kesehatan, dan pangan (Yustiningrum, 2016). Kerentananan dapat menyebabkan penurunan kualitas hidup korban dan infrastruktur fisik yang merupakan sistem pendukung kehidupan bagi korban bencana gempa bumi. Rumah tangga dalam menghadapi perubahan pendapatan yang terjadi secara tiba-tiba dan bersifat sementara, rumah tangga melakukan penyesuaian untuk mempertahankan utilitas marginal dari komsumsi (Mankiw N. Gregory, 2000). Pengetahuan merupakan faktor penting untuk menjadi kunci sukses ketahanan dalam menghadapi bencana gempa bumi. Selain itu, berdasarkan kenyataan tersebut maka perlu adanya penyediaan dan pelayanan yang cepat serta akurat dalam memberikan informasi seputar bencana gempa bumi karena hal tersebut memegang peranan penting sebagai upaya tanggap darurat ataupun mitigasi bencana. Hal ini sangat penting dilakukan guna untuk meminimalisir dampak dan korban akibat terjadinya gempa bumi yang dapat terjadi sewaktu-waktu

Cara yang dilakukan rumah tangga untuk mengurangi dampak perubahan pendapatan yang terjadi tiba-tiba akibat terjadinya bencana gempa bumi yaitu dengan cara strategi bertahan hidup. Strategi yang dipilih bagi seseorang atau rumah tangga bisa beragam agar dapat mencapai outcomes penghidupan yaitu peningkatan pendapatan, kesejahteraan, bahkan sumber penghidupan yang dilakoninya dapat 
meningkat dan memiliki daya tahan terhadap situasi kerentanan yang melingkupinya. Strategi yang digunakan rumah tangga dapat dibagi menjadi 2 yaitu strategi mempertahankan hidup dalam jangka pendek dan strategi mempertahankan hidup rumah tangga dalam jangka panjang. Pengkategorian keberhasilan kesejahteraan masyarakat menggunakan istilah strategi yang digunakan oleh (White, B., Boomgaard P. dan Alexander, 1991) yaitu meliputi, survival, konsolidasi, dan akumulasi.

\section{METODE}

Penelitian ini merupakan jenis penelitian kualitatif dengan menggunakan metode studi kasus. Cara pengambilan sampel menggunakan purposive sampling. Sampel yang digunakan dalam penelitian ini yaitu dengan memilih satu Kecamatan di Lombok Utara. Jumlah sampel yang digunakan dalam penelitian ini yaitu sebanyak 60 rumah tangga. Data yang digunakan dalam penelitian ini yaitu data primer dan data sekunder. Data primer diperoleh melalui informan yang secara langsung memberikan informasi yang diperlukan peneliti. Sedangkan, untuk data sekunder diperoleh secara tidak langsung dari informan yaitu didapat mellalui instansi pemerintahan yang terkait dalam penelitian ini. Alat pengumpulan data dalam penelitian ini yaitu dengan menggunakan panduan wawancara. Teknik pengumpulan data dalam penelitian ini menggunakan triangulasi. Triangulasi yang digunakan dalam penelitian ini yaitu dengan menggunakan triangulasi sumber. Selain itu, teknik pengumpulan data lainnya yaitu berupa observasi, wawancara mendalam, dan dokumentasi. Analisis data yang digunakan dalam penelitian ini adalah analisis kualitatif dengan menggunakan model Miles dan Huberman. Aktivitas yang dilakukan dalam analisis tersebut yaitu berupa data penskoran, reduction, data display, dan conclusion drawing/verification. Penentuan strategi penghidupan dalam penelitian ini menggunakan teori menurut (Scoones I, 1998) yang disesuaikan dengan kondisi di daerah penelitian yaitu membedakan menjadi 2 (dua) kelompok yaitu antara lain: Intensifikasi dan Diversifikasi.

HASIL

\section{HASIL DAN PEMBAHASAN}

Cara yang dilakukan rumah tangga untuk mengurangi dampak perubahan pendapatan tiba-tiba akibat terjadinya bencana gempa bumi yaitu dengan cara strategi bertahan hidup. Strategi yang digunakan bermacam-macam jenisnya antara lain dengan cara sebagai berikut.

\section{a. Strategi intensifikasi}

Strategi ini meliputi pemanfatan lahan pertanian, dan pekarangan sebagai cara pemenuhan hidup dalam proses pemulihan pasca gempa bumi. Berdasarkan dari 60 responden penelitian mayoritas sebanyak 36 (60\%) RT menyatakan mereka memiliki lahan pertanian berupa ladang, kebun maupun sawah. Masing-masing rumah tangga memiliki luas lahan pertanian yang berbeda-beda dari yang paling terkecil 1 hektar hingga lebih dari 2 hektar. Masing-masing lahan pertanian yang dimiliki rumah tangga dimanfaatkan dengan caranya tersendiri.

Beberapa dari rumah tangga terdapat juga yang memanfaatkan lahan pekarangan mereka untuk kegiatan lain yaitu dengan ditanami tanaman buahbuahan dan dimanfaatkan untuk menjemur hasil kebun, dan sebagai kandang ternak. Tanaman buah-buahan yang ditemui yaitu pisang dan kelapa. Selain itu, pekarangan yang digunakan sebagai kandang ternak yaitu mayoritas ayam, dan sapi. Berikut ini gambar 1 dan gambar 2 merupakan salah satu rumah tangga yang memanfaatkan lahan pekarangan untuk memelihara ternak sebagai berikut. 

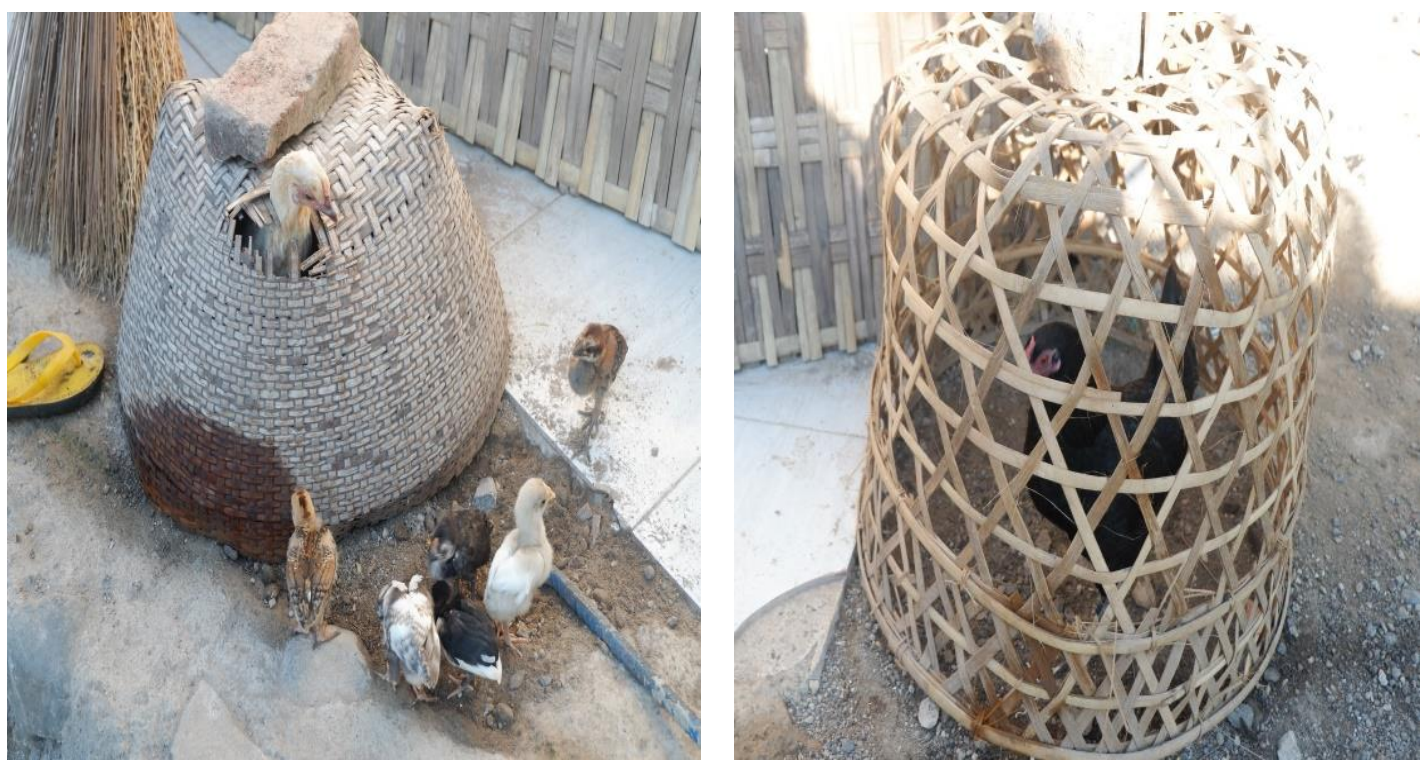

Gambar 1. Salah satu rumah yang memanfaatkan lahan pekarangan untuk memelihara ternak ayam

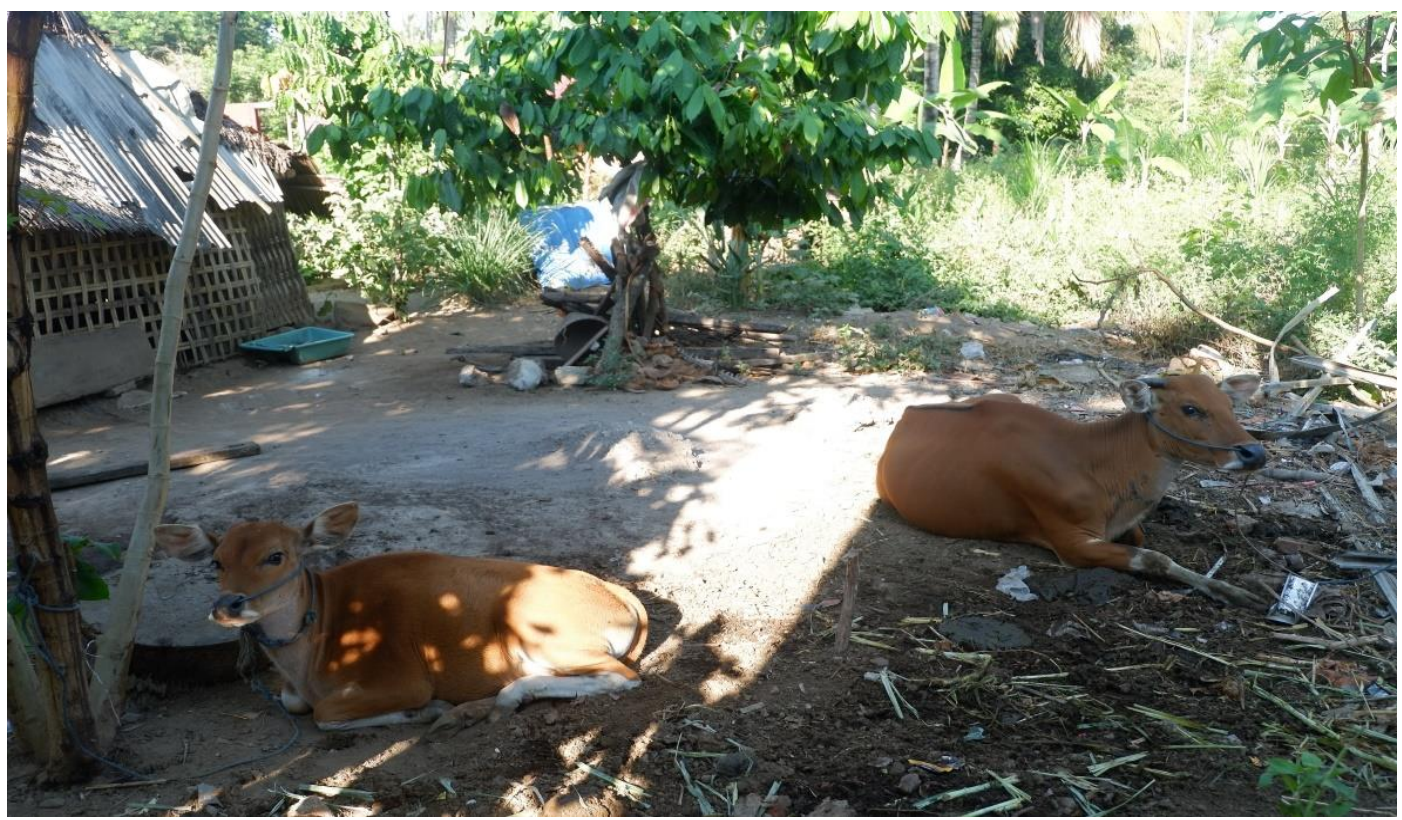

Gambar 2. Salah satu rumah yang memanfaatkan lahan pekarangan untuk memelihara ternak sapi

Ternak yang biasanya dipelihara yaitu jenis ayam atau itik, dan sapi. Mayoritas rumah tangga memelihara hewan tersebut di pekarangannya agar mudah untuk mengawasi hewan tersebut. Secara intensifikasi terdapat juga kegiatan lain yang dilakukan oleh masyarakat yaitu dengan memanfaatkan lahan pekarangan untuk menjemur hasil kebun. Hasil kebun yang biasanya dijemur di halaman berupa biji kopi. Berikut ini gambar 3 merupakan salah satu rumah yang memanfaatkan lahan pekarangan untuk menjemur hasil kebun berupa kopi sebagai berikut. 


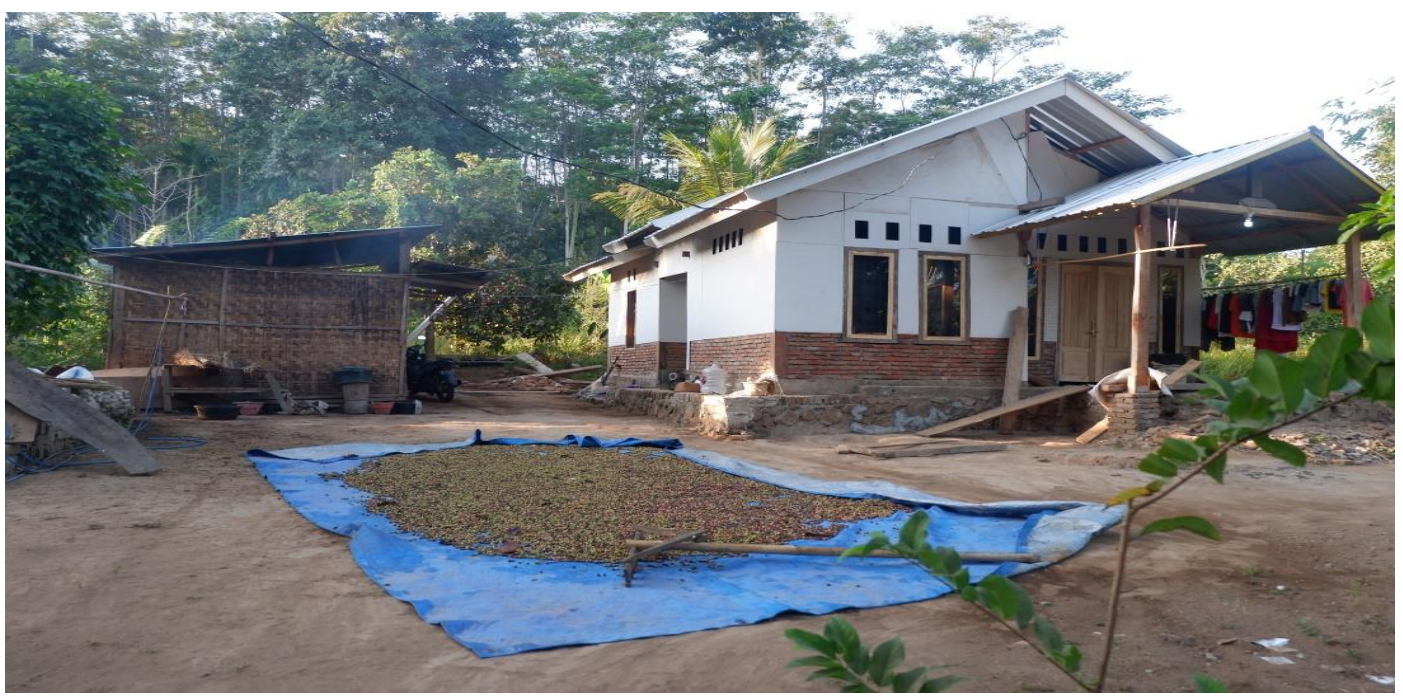

Gambar 3. Salah satu rumah yang memanfaatkan lahan pekarangan untuk menjemur hasil kebun berupa kopi

Pemanfaatan lahan pertanian lain yaitu berupa ladang, perkebunan, dan sawah. Rumah tangga di kecamatan ini memanfaatkan ladang untuk ditanami tanaman palawija, jambu mete, pisang, nangka, jagung, dan kacang tanah. Sedangkan, pemanfaatan lahan pertanian lain yang berupa perkebunan dimanfaatkan untuk ditanami kopi, kelapa, kakao, dan cengkeh.

\section{b. Strategi Diversifikasi}

Kegiatan ekonomi perdesaan tidak hanya semata-mata digunakan pada sektor pertanian. Bermacam-macam aktivitas lainnya turut mempengaruhi ekonomi perdesaan. Strategi diversifikasi yang dilakukan rumah tangga di Kecamatan Kayangan yaitu antara lain meliputi kegiatan pertanian diluar bercocok tanam, sektor perdagangan, sektor jasa, penghasilan dari modal, pengolahan dan pemasaran hasil pertanian. Berdasarkan pada penelitian terhadap 60 rumah tangga yang dijadikan sebagai responden, strategi diversifikasi rumah tangga di Kecamatan Kayangan mayoritas melakukan kegiatan pertanian diluar bercocok tanam sebanyak $24(40 \%)$ RT. Kegiatan diluar bercocok tanam yang paling banyak dilakukan adalah peternakan. Peternakan yang dilakukan yaitu ternak ayam dan sapi. Hal ini karena masyarakat memilih beternak dengan alasan kegiatan tersebut lebih mudah dilakukan pasca gempa bumi. Alasan lainnya karena banyaknya masyarakat yang kehilangan pekerjaan dan ada juga yang lahan pertaniannya mengalami kerusakan sehingga mereka memilih kegiatan beternak ayam atau sapi. Selain itu, ada juga yang melakukan kegiatan ternak kambing tetapi hanya beberapa saja. Sedangkan untuk diversifikasi melalui sektor perdagangan dilakukan oleh $8(13,33 \%)$ RT. Kegiatan perdagangan ini terdiri dari membuka toko atau warung sembako, berdagang dipasar, maupun kegiatan perdagangan lainnya. Jenis toko terbanyak yang dijadikan kegiatan perdangangan oleh masyarakat di daerah ini yaitu warung sembako. Hal ini karena warung sembako menjadi alternatif dalam memenuhi kebutuhan pokok masyarakat sekitar karena lokasi pasar di daerah tersebut yang cukup jauh.

Kegiatan diversifikasi melalui sektor jasa di Kecamatan Kayangan dilakukan oleh 20 (33,33\%) RT. Kegiatan di sektor ini yaitu didominasi oleh buruh tani, buruh bangunan, nelayan, buruh traktor dan sopir. Selain itu, terdapat sebanyak 3 (5\%) RT yang melakukan diversifikasi dalam sektor dan pemasaran. Kegiatan dalam 
sektor pengolahan dan pemasaran memang belum banyak dilakukan di kecamatan ini. Hanya ada beberapa rumah tangga yang sudah melakukan kegiatan di sektor ini. Pengolahan dan pemasaran yang dilakukan salah satunya yaitu tanaman kopi.

Pengolahan dilakukan pada tanaman kopi hingga menjadi biji kopi, sehingga selanjutnya dapat dipasarkan. Pemasaran biasanya dilakukan langsung oleh petani kebun untuk dijual kepada pedagang atau tengkulak. Responden hanya fokus terhadap cara untuk meningkatkan produksi lahannya. Selain itu, dengan menjual kepada pedagang atau tengkulak akan menjamin barang produksi atau hasil pertaniannya laku terjual jika dibandingkan petani kebun tersebut menjual hasilnya sendiri. Berikut ini tabel 1 menunjukkan kegiatan strategi diversifikasi yang dilakukan rumah tangga di Kecamatan Kayangan sebagai berikut.

Tabel 1 Kegiatan Strategi Diversifikasi

\begin{tabular}{lcc}
\hline \multicolumn{1}{c}{ Kegiatan } & Jumlah (Rumah Tangga) & $\begin{array}{c}\text { Persentase } \\
(\%)\end{array}$ \\
\hline Pertanian diluar bercocok tanam & 24 & 40 \\
Sektor pedagangan & 8 & 13,33 \\
Sektor jasa & 20 & 33,33 \\
Penghasilan dari modal & 0 & 0 \\
Pengolahan dan pemasaran & 3 & 5 \\
Tidak ada kegiatan strategi diversifikasi & 5 & 8,34 \\
\hline Jumlah & 60 & 100 \\
\hline
\end{tabular}

\section{PEMBAHASAN}

Rumah tangga dalam menghadapi perubahan pendapatan yang terjadi secara tiba-tiba dan bersifat sementara, rumah tangga melakukan penyesuaian untuk mempertahankan utiilitas marginal dari komsumsi (Mankiw N. Gregory, 2000). Cara yang dilakukan rumah tangga untuk mengurangi dampak perubahan pendapatan yang terjadi tiba-tiba akibat terjadinya bencana gempa bumi yaitu dengan cara strategi bertahan hidup. Strategi yang digunakan rumah tangga dapat dibagi menjadi 2 yaitu strategi mempertahankan hidup dalam jangka pendek dan strategi mempertahankan hidup rumah tangga dalam jangka panjang.

Berdasarkan (Scoones I, 1998) mengelompokan strategi penghidupan menjadi 3 yaitu antara lain, intensifikasi dan eksensifikasi, diversifikasi, dan migrasi. Berdasarkan hasil penelitian di Kecamatan Kayangan mengenai strategi penghidupan yang dipilih oleh rumah tangga pasca gempa bumi terjadi yaitu meliputi pemanfatan lahan pertanian, dan pemafaatan lahan pekarangan sebagai cara pemenuhan hidup dalam proses pemulihan pasca gempa bumi. Hal ini sesuai dengan penelitian yang dilakukan oleh (Wijayanti, 2016) strategi intensifikasi lahan pertanian dilakukan dengan cara mengusahakan lebih dari satu jenis tanaman pada satu lahan pertanian pada waktu yang bersamaan. Berdasarkan dari 60 responden penelitian mayoritas sebanyak $36(60 \%)$ RT menyatakan mereka memiliki lahan pertanian baik berupa ladang, kebun maupun sawah.

Beberapa dari rumah tangga terdapat juga yang memanfaatkan lahan pekarangan mereka untuk kegiatan lain yaitu dengan ditanami tanaman buahbuahan dan dimanfaatkan untuk menjemur hasil kebun, dan sebagai kandang ternak. Tanaman buah-buahan sendiri yang sering ditemui yaitu pisang dan kelapa yang terdapat di pekarangan. Selain itu, pekarangan yang digunakan sebagai kandang ternak yaitu mayoritas ayam, dan sapi. Mayoritas rumah tangga memelihara hewan tersebut di pekarangannya agar mudah untuk mengawasi hewan tersebut. Selain itu, ada kegiatan lain yaitu dengan memanfaatkan lahan pekarangan untuk menjemur hasil kebun. Hasil kebun yang biasanya dijemur di 
halaman berupa biji kopi. Pemanfaatan lahan pertanian lain yaitu berupa ladang, perkebunan, dan sawah. Rumah tangga di kecamatan ini memanfaatkan ladang untuk ditanami tanaman palawija, jambu mete, pisang, nangka, jagung, dan kacang tanah. Sedangkan, pemanfaatan lahan pertanian lain yang berupa perkebunan dimanfaatkan untuk ditanami kopi, kelapa, kakao, dan cengkeh.

Berdasarkan hasil, strategi diversifikasi rumah tangga di Kecamatan Kayangan mayoritas melakukan kegiatan pertanian diluar bercocok tanam sebanyak 24 (40\%) $\mathrm{RT}$. Kegiatan diluar bercocok tanam di kecamatan ini yang paling banyak dilakukan adalah peternakan. Peternakan yang dilakukan yaitu ternak ayam dan sapi. Selain itu ada juga yang melakukan kegiatan ternak kambing tetapi hanya beberapa saja. Sedangkan untuk diversifikasi melalui sektor perdagangan dilakukan oleh 8 $(13,33 \%)$ RT. Kegiatan perdagangan ini terdiri dari membuka toko atau warung sembako, berdagang dipasar, maupun kegiatan perdagangan lainnya.

Kegiatan diversifikasi melalui sektor jasa di Kecamatan Kayangan dilakukan oleh $20(33,33 \%)$ RT. Kegiatan di sektor ini yaitu didominasi oleh buruh tani, buruh bangunan, nelayan, buruh traktor dan sopir. Sedangkan untuk kegiatan diversifikasi melalui sektor penghasilan yang berasal dari kepemilikan modal atau harta. Misalnya, dari deposito, deviden, sisa hasil usaha (SHU) koperasi, asuransi,persewaan, maupun lainnya. Tidak ada rumah tangga yang melakukan deivertisifikasi dalam sektor penghasilan dari modal atau harta di kecamatan ini. Selain itu, terdapat sebanyak $3(5 \%)$ RT yang melakukan diversifikasi dalam sektor dan pemasaran. Kegiatan dalam sektor pengolahan dan pemasaran memang belum banyak dilakukan di kecamatan ini. Hanya ada beberapa rumah tangga yang sudah melakukan kegiatan di sektor ini. Pengolahan dan pemasaran yang dilakukan salah satunya yaitu tanaman kopi. Pengolahan dilakukan pada tanaman kopi hingga menjadi biji kopi, sehingga selanjutnya dapat dipasarkan. Pemasaran biasanya dilakukan langsung oleh petani kebun untuk dijual kepada pedagang atau tengkulak. Responden hanya fokus terhadap cara untuk meningkatkan produksi lahannya. Selain itu, dengan menjual kepada pedagang atau tengkulak akan menjamin barang produksi atau hasil pertaniannya laku terjual jika dibandingkan petani kebun tersebut menjual hasilnya sendiri.

\section{SIMPULAN}

Bentuk strategi penghidupan rumah tangga yang terdapat di Kecamatan Kayangan pasca gempa bumi yaitu intensifikasi dan eksensifikasi, serta diversifikasi. Bentuk strategi intensifikasi dan eksensifikasi yang dilakukan rumah tangga di Kecamatan Kayangan yaitu berupa pemanfatan lahan pertanian, dan pemafaatan lahan pekarangan sebagai cara pemenuhan hidup dalam proses pemulihan pasca gempa bumi. Mayoritas sebanyak $36(60 \%)$ RT menyatakan mereka memiliki lahan pertanian baik berupa ladang, kebun maupun sawah. Sedangkan, bentuk strategi diversifikasi yang diakukan rumah tangga di Kecamatan Kayangan yaitu meliputi kegiatan pertanian diluar bercocok tanam, sektor perdagangan, sektor jasa, penghasilan dari modal, pengolahan dan pemasaran hasil pertanian. Mayoritas melakukan kegiatan pertanian diluar bercocok tanam sebanyak 24 (40\%) RT. Berdasarkan kesimpulan diatas, maka hasil penelitian ini mempunyai implikasi yaitu penelitian ini dapat dijadikan sebagai rekomendasi khususnya untuk pemerintah daerah setempat selaku pemegang kekuasaan dalam pembuatan kebijakan maupun untuk perkembangan ilmu pengetahuan. Selain itu, perlunya penguatan lembaga kemasyarakatan perlu dilakukan pembinaan karena bagi masyarakat lembaga tersebut memiliki peran yang besar dalam memberikan dukungan dan gotong-royong saat terjadi keadaaan darurat. 


\section{DAFTAR PUSTAKA}

Amri, M. R., Yulianti, G., Yunus, R., Wiguna, S., Adi, A. W., Ichwana, A. N., ... Septian, R. T. (2006). Risiko Bencana Indonesia, 218 pp.

Christanto, J. (2011). Gempa Bumi, Kerusakan Lingkungan, Kebijakan dan Strategi Pengelolaan. Yogyakarta: Liberty.

Hartuti, E. R. (2009). Buku Pintar Gempa. Yogyakarta: DIVA Press.

Hermon, D. (2015). Geografi Bencana Alam. Jakarta: Rajawali Pers.

Mankiw N. Gregory. (2000). Teori Ekonomi Makro (Terjemahan). Jakarta: Edisi Keempat, Erlangga.

National Agency for Disaster Management (BNPB). (2015). National Disaster Management Plan(RENCANA NASIONAL PENANGGULANGAN BENCANA). Retrieved from https://www.bnpb.go.id//uploads/renas/1/BUKU RENAS PB.pdf

Scoones I. (1998). Sustainable rural livelihoods: A framework for analysis. Working Paper, 72.

Sukandarrumidi. (2010). Bencana Alam \& Bencana Anturopogene. Yogyakarta: Kanisius.

White, B., Boomgaard P. dan Alexander, P. (Editors). (1991). In Shadow of Agriculture, Non-farm Activities in the Javanese Economy, Past and Present. Amsterdam: Royal Tropical Institute.

Wiarto, G. (2017). Tanggap Darurat Bencana Alam. Yogyakarta: Gayen Publishing.

Wijayanti, R. (2016). Strategi Penghidupan Berkelanjutan Masyarakat Berbasis Aset di Sub DAS Pusur , DAS Bengawan Solo, 4, 133-152. https://doi.org/10.14710/jwl.4.2.133-152.

Yustiningrum, R. E. (2016). Bencana Alam, Kerentanan dan Kebijakan di Indonesia; Studi Kasus Gempa Padang dan Tsunami Mentawai. Yogyakarta: Calpulis. 